\title{
Amosite Asbestos
}

National Cancer Institute

\section{Source}

National Cancer Institute. Amosite Asbestos. NCI Thesaurus. Code C45527.

A naturally occurring, fibrous amphibole asbestos mineral with a color ranging from gray to greenish-brown. Amosite is used extensively in industry for various purposes. Chronic inhalation of its dust may cause asbestosis and increases the risk of respiratory tract cancer, mesothelioma and other lung cancers. Amosite asbestos is a known human carcinogen. ( $\mathrm{NCl05})$ 